Www.jmscr.igmpublication.org

Index Copernicus Value: 79.54

ISSN (e)-2347-176x ISSN (p) 2455-0450

crossrefDOI: https://dx.doi.org/10.18535/jmscr/v7i3.07

\title{
Prevalence of Hypertension, Obesity and Its Influence on Achievement of Therapeutic Goals in Indian Type 2 Diabetes Patients: A retrospective observational study at tertiary diabetes care centre in Bihar
}

\author{
Author \\ Dr Akhouri Sukrit Prakash \\ Sr. Diabetologist, Prakash Diabetes Speciality Hospital, Patna, Bihar, India
}

\begin{abstract}
Aim: The present study was conducted to observe the prevalence of hypertension, obesity and its Influence on Achievement of Therapeutic Goals in Type 2 Diabetes Patients who were attending diabetes care centre in Bihar.

Method: The observational study was undertaken at Prakash diabetes care hospital at Patna city in Bihar. A total sample of 1400 type 2 diabetes patients attending the medical outdoor patient department were studied to assess the prevalence hypertension, obesity and its influence on achievement of therapeutic goals. Anthropometric data was collected by using standard questionnaire by measuring body weight, height, west circumference and hip circumference. A mercury sphygmomanometer (Diamond Deluxe Blood Pressure apparatus, Pune, India) was used to determine the sitting blood pressure of right arm. Glycated haemoglobin (HbAlc) test was performed at hospital laboratory to determine glycemic level.

Result: There were $42.6 \%$ subjects who were overweight and 18.2\% type 2 diabetes patents were obese. Prevalence of hypertension was $79.8 \%$ in this category of subjects. Among this subjects target goals were achieved by $12.6 \%$ of subjects who were overweight and $9.6 \%$ of subjects who were obese. The subjects who were having normal BMI among both over weight and obese were less likely to achieve target glycemic goal. It was also observed that prevalence of hypertension, obesity was quite high in type 2 diabetic patients of Patna city. Subjects who had abdominal obesity with hypertension were unable to achieve target glycemic control than those without abdominal obesity and hypertension.

Conclusion: Hypertension and obesity were associated with poor glycemic control in Indian type 2 diabetes patients mainly receding at Bihar. To manage the situation a proper clinical awareness and management of obesity and hypertension is essential with lifestyle modification and strict exercise to achieve target glycemic control among type 2 diabetes subjects.

Keywords: Hypertension, Obesity, Diabetes, BMI, west circumference.
\end{abstract}

\section{Introduction}

In $21^{\text {st }}$ centuries one of the largest global health emergencies is diabetes. A recent publication ${ }^{[1]}$ already confirmed that prevalence of diabetes varied from $4.3 \%$ in Bihar (95\% CI 3.7-5.0) to $10.0 \%(8.7-11.2)$ and was higher in urban areas
$(11.2 \%, 10.6-11.8)$ than in rural areas $(5.2 \%$, $4 \cdot 9-5 \cdot 4 ; \mathrm{p}<0 \cdot 0001)$ and higher in mainland states $(8.3 \%, 7 \cdot 9-8.7)$ than in the northeast $(5.9 \%, 5 \cdot 5-$ $6 \cdot 2 ; \mathrm{p}<0 \cdot 0001)$. The risk of developing type 2 diabetes is higher among people who are overweight or obese ${ }^{[2]}$. Approximately $85 \%$ of 
people with diabetes are overweight or obese ${ }^{[3]}$. Incidence of increasing global prevalence of type 2 diabetes (T2DM) principally driven by obesity epidemic which is now become well established and accepted ${ }^{[4]}$. As by improvement in standards of living ${ }^{[5]}$ there was a rapid increase in aging and urbanizing $^{[6]}$ among Indian population which is lead to increase in obesity and its associated cardiovascular disease (CVD) risk factors, including diabetes and hypertension. Geldsetzer P et $\mathrm{al},{ }^{[7]}$ has already confirmed that diabetes and hypertension prevalence is high in middle and old age across all geographical areas and sociodemographic groups in India, and hypertension prevalence among young adults is higher than previously thought. Sharma et al, has observed that, there is a 2-3 folds increase in prevalence of T2DM among obese patients, among moderately obese it increases up to 5 folds and it reaches maximum of 10 folds to severely obese patients ${ }^{[8]}$. Excess body weight was attributed to approximately $90 \%$ of T2DM patients which has been estimated by Hossain et $\mathrm{al}^{[9]}$. Arner et $\mathrm{al}^{[10]}$ even confirmed that excess weight is more common in newly diagnosed T2DM compare to non-diabetic subjects.

It is of paramount importance to determine the prevalence of major risk factors like obesity and hypertension and its influence on achievement of therapeutic goals in Type 2 Diabetes patients who were attending diabetes care centre in Bihar, which was never done here earlier.

\section{Methods}

The observational study was undertaken at Prakash diabetes care hospital at Patna city in Bihar from 02 Jan 2017 to November 2018.Prakash Diabetes Speciality Hospital is a specialty care diabetes Centre with state-of-the-art technology and providing sophisticated and specialized medical services at affordable costs in Diabetes and its related specialties in Patna city. A total sample of 1400 type 2 diabetes patients attending the medical outdoor patient department were studied to assess the prevalence hypertension, obesity and its influence on achievement of therapeutic goals. Before study, Institutional Ethical committee approval was taken and an informed consent was obtained from all the subjects after explaining the objectives of the study.

Personal interview was conducted before enrolment of the study with help of predesigned questioner. Anthropometric data was collected by using standard questionnaire by measuring body weight, height, west circumference and hip circumference. A mercury sphygmomanometer (Diamond Deluxe Blood Pressure apparatus, Pune, India) was used to determine the sitting blood pressure of right arm. Glycated haemoglobin (HbA1c) test was performed at hospital laboratory to determine glycemic level.

Height was measured in centimetres (to the nearest 0.1 centimeter) by anthropometric steel rod with subjects standing in erect position with barefooted. Weight was measure by a calibrated weighing automatic machine with subjects standing in erect position with wearing minimum clothes. A non-stretchable measuring tape was used to measure waist and hip circumferences in centimetres. Waist circumference (WC) was measured in midway between iliac crest and lowermost margin of ribs. According to guidelines, cut-offs for waist circumstances was $90 \mathrm{~cm}$ for Indian men (as opposed to $102 \mathrm{~cm}$ globally) and $80 \mathrm{~cm}$ for Indian women (as opposed to $88 \mathrm{~cm}$ at the international level $)^{[11]}$. At the level of the greater trochanters Hip circumference (HC) was measured in centimetres. Body Mass Index (BMI) was calculated as weight in kilograms divided by squared height in meters (weight in $\mathrm{kg} / \mathrm{height}$ in $\mathrm{m} 2$ ). Normal weight when BMI > 18.5-<23.0 Kg/m ${ }^{2}$ and overweight when $\mathrm{BMI} \geq 23.0 \mathrm{Kg} / \mathrm{m}^{2}$. Waist-Hip Ratio (WHR) was calculated using following formula: $\mathrm{WHR}=\mathrm{WC}$ $(\mathrm{cm}) / \mathrm{HC}(\mathrm{cm})$. Recommended WHO criteria for elevated WHR $=0.95$ for males and 0.88 for females. All patients were then categorized as obese or non-obese using BMI \& Waist Circumference (WC) \& WHR as diagnostic 
parameters. Diagnosis of T2DM was based on American Diabetes Association (ADA) recommendation i.e., in subjects whose glycated haemoglobin $\mathrm{HbAlC} \geq 6.5 \%(48 \mathrm{mmol} / \mathrm{mol})^{[12]}$. Obesity was defined by International Diabetes Federation (IDF) criteria as the presence of any one or more of the following parameters i.e., BMI $>23 \mathrm{Kg} / \mathrm{m} 2, \mathrm{WC}:>90 \mathrm{~cm}$ (Male) and WC : > $80 \mathrm{~cm}$ (Female) ${ }^{[13]}$.

Inclusion Criteria: The study included patients who were attended the diabetes and medicine outdoor patient department of Prakash diabetes care hospital and having type 2 diabetes and nondiabetic between the age group of 20-70 years.

Exclusion criteria: Patient with existing vascular complication, with any previous $\mathrm{CV}$ event, pregnancy or lactating woman.
Statistical Analysis: The whole data was entered into computer using MS-Excel program. The data was analysed using Statistical Software for Social Sciences for Windows version 16.0 (SPSS Inc., Chicago, IL). The students " $\mathrm{t}$ " - test and "chice square tests were used to find out the statistical significance of the results.

\section{Result}

899 subjects were belongs to age group of 40-60 which is maximum out of 1400 subjects. 869 subjects were female and 531 were male.

Prevalence of obesity was $63 \%$ as per the BMI criteria ( $\geq 25$ ) Prevalence of hypertension was 53 $\%$.( Table 1)

Table 1: Association of BMI with hypertension among T2DM subjects

\begin{tabular}{|l|c|c|c|}
\hline \multirow{2}{*}{ BMI } & \multicolumn{3}{|c|}{ Blood pressure } \\
\cline { 2 - 3 }$\geq 25$ & Hypertensive & Normotensive & significance \\
\hline$<25$ & 470 & 411 & $2^{2}$ cal $=6.29$, \\
d.f. $=1$, \\
$\mathrm{p}<0.05$
\end{tabular}

Out of 531, 263 male subjects were hypertensive of which 211 had WC of 90 or more, the association of hypertension and obesity (central) was not statistically significant. Out of 339 hypertensive female subjects, 317 had WC of 80 or more obese (central), the association of central obesity with hypertension in female is statistically significant.

Table 2: Association of waist circumference and hypertension among T2DM subjects

\begin{tabular}{|c|c|c|c|}
\hline \multirow{2}{*}{$\begin{array}{l}\text { Waist } \\
\text { circumference }\end{array}$} & \multicolumn{3}{|c|}{ Blood pressure } \\
\hline & Hypertensive & Normotensive & Significance \\
\hline \multicolumn{4}{|l|}{ Males(n=531) } \\
\hline$\geq 90$ & 211 & 80 & \multirow{2}{*}{$\begin{array}{c}\mathrm{x}^{2} \mathrm{cal}=1.9 \\
\mathrm{p}>0.05\end{array}$} \\
\hline$<90$ & 70 & 170 & \\
\hline \multicolumn{4}{|l|}{ Females $(\mathrm{n}=869)$} \\
\hline$\geq 80$ & 267 & 133 & \multirow{2}{*}{$\begin{array}{c}\mathrm{x}^{2} \mathrm{cal}=10.65 \\
\mathrm{p}>0.05\end{array}$} \\
\hline$<80$ & 60 & 409 & \\
\hline
\end{tabular}

The demographic and clinical characteristics of the 1,400 patients with type 2 diabetes were stratified by BMI and WC and are shown in Table 3. Patients were having long duration of diabetes with comorbid condition. Sedentary lifestyle and
Alcohol consumption were more common in obese than in normal-weight patients. Centrally obese patients were also more likely to be smokers or alcohol drinkers $(\mathrm{P}<0.001)$. 
Table 3: Demographic and clinical characteristics of diabetes patients stratified by BMI and WC

\begin{tabular}{|c|c|c|c|c|c|c|c|}
\hline & \multirow{2}{*}{$\begin{array}{c}\text { Total } \\
(n=1400)\end{array}$} & \multicolumn{3}{|c|}{ BMI $\left(\mathrm{kg} / \mathrm{m}^{2}\right)$} & \multicolumn{3}{|c|}{ BMI $\geq 25 \mathrm{~kg} / \mathrm{m}^{2}$} \\
\hline & & $\begin{array}{c}<25 \\
(n=519)\end{array}$ & $\begin{array}{c}\geq 25 \\
(n=881)\end{array}$ & P Value & $\begin{array}{c}\text { Normal WC } \\
(n=190)\end{array}$ & $\begin{array}{l}\text { Central } \\
\text { obesity } \\
(n=691)\end{array}$ & $\begin{array}{c}\mathbf{P} \\
\text { Value }\end{array}$ \\
\hline Age, years (mean \pm SD) & $52.5 \pm 11.3$ & $53.5 \pm 11.6$ & $52.2 \pm 11.5$ & $<0.001$ & $53.1 \pm 11.2$ & $52.8 \pm 11.8$ & $<0.001$ \\
\hline$<40$ & $112(8 \%)$ & $31(6 \%)$ & $81(9.1 \%)$ & \multirow{3}{*}{$<0.001$} & $15(7.8 \%)$ & $66(9.5 \%)$ & \multirow{3}{*}{$<0.001$} \\
\hline $40-60$ & $899(64.2 \%)$ & $353(68 \%)$ & $\begin{array}{c}546 \\
(61.9 \%)\end{array}$ & & $123(64.7 \%)$ & $\begin{array}{c}423 \\
(61.2 \%)\end{array}$ & \\
\hline$>60$ & $389(27.8 \%)$ & $\begin{array}{c}112 \\
(21.57 \%) \\
\end{array}$ & $\begin{array}{c}277 \\
(31.4 \%) \\
\end{array}$ & & $52(30.1 \%)$ & $\begin{array}{c}225 \\
(32.56 \%) \\
\end{array}$ & \\
\hline Male & 531 & 196 & 335 & $<0.001$ & 72 & 263 & $<0.001$ \\
\hline Diabetes duration, years & $4.1 \pm 1.6$ & $4.2 \pm 1.8$ & $4 \pm 1.2$ & $<0.001$ & $4 \pm 1.3$ & $3.8 \pm 1.1$ & $<0.001$ \\
\hline$<1$ & $118(8.4 \%)$ & $40(7.7 \%)$ & $78(8.8 \%)$ & \multirow[t]{3}{*}{$<0.001$} & $19(10 \%)$ & $59(8.5 \%)$ & \multirow[t]{3}{*}{$<0.001$} \\
\hline $1-5$ & $984(70.3 \%)$ & $\begin{array}{c}381 \\
(73.4 \%)\end{array}$ & $603(68 \%)$ & & $142(74.7 \%)$ & $\begin{array}{c}461 \\
(66.7 \%)\end{array}$ & \\
\hline$>5$ & $298(21.3 \%)$ & $121(23 \%)$ & $\begin{array}{c}177 \\
(20.1 \%) \\
\end{array}$ & & $49(25.8 \%)$ & $\begin{array}{c}128 \\
(18.5 \%) \\
\end{array}$ & \\
\hline Dyslipidemia & $381(27.2 \%)$ & $29(5.6 \%)$ & $352(40 \%)$ & $<0.001$ & $51(26.8 \%)$ & $\begin{array}{c}301 \\
(43.6 \%)\end{array}$ & $<0.001$ \\
\hline $\begin{array}{l}\text { Dyslipidemia } \\
\text { hypertension }\end{array}$ & $308(22 \%)$ & $18(3.5 \%)$ & $\begin{array}{c}290 \\
(32.9 \%)\end{array}$ & $<0.001$ & $44(23.15 \%)$ & $\begin{array}{c}246 \\
(35.6 \%)\end{array}$ & $<0.001$ \\
\hline Smoking & $231(16.5 \%)$ & $\begin{array}{c}86 \\
(16.6 \%)\end{array}$ & $\begin{array}{c}145 \\
(16.5 \%)\end{array}$ & $<0.001$ & $32(16.8 \%)$ & $\begin{array}{c}113 \\
(16.4 \%)\end{array}$ & $<0.001$ \\
\hline Alcohol consumption & $112(8 \%)$ & $37(7.1 \%)$ & $75(8.5 \%)$ & $<0.001$ & $17(8.94 \%)$ & $58(8.4 \%)$ & $<0.001$ \\
\hline Sedentary lifestyle & $521(37.2 \%)$ & $\begin{array}{c}188 \\
(36.2 \%)\end{array}$ & $\begin{array}{c}333 \\
(37.8 \%)\end{array}$ & $<0.001$ & $69(36.3 \%)$ & $\begin{array}{c}264 \\
(38.2 \%)\end{array}$ & $<0.001$ \\
\hline
\end{tabular}

Data are shown as mean \pm SD or $\mathrm{n}(\%)$.

A total of $45.8 \%$ of the patients reached the recommended glycemic control target $(\mathrm{HbA} 1 \mathrm{c}<7 \%) ; 42.4 \%$ achieved the BP target $(<140 / 90 \mathrm{mmHg})$, and $43.4 \%$ reached the lipid control target (LDL-C $<100 \mathrm{mg} / \mathrm{dl}$ ). All target goals (i.e., control of HbA1c, BP, and LDL-C) were achieved by $19 \%$ of the study participants. A total of $84.7 \%$ of normal-weight patients achieved
HbA1c control, 79.8\% achieved BP control, and $34.7 \%$ achieved all the target goals compared with $22.8 \%, 20.3 \%, 21.9 \%$ and $9.9 \%$ of obese patients, respectively $(\mathrm{P}<0.001)$. A similar trend was seen in centrally obese patients, suggesting that patients who had an abnormal BMI and an abnormal WC were at increased risk of failure to achieve target therapeutic goals.

Table 4: Profiles andgoal attainment rates of diabetes patients stratified by BMI and WC.

\begin{tabular}{|c|c|c|c|c|c|c|c|}
\hline & \multirow{2}{*}{$\begin{array}{c}\text { Total } \\
(n=1400)\end{array}$} & \multicolumn{3}{|c|}{ BMI (kg/m²) } & \multicolumn{3}{|c|}{ BMI $\geq 25 \mathrm{~kg} / \mathrm{m}^{2}$} \\
\hline & & $\begin{array}{c}<25 \\
(n=519)\end{array}$ & $\begin{array}{c}\geq 25 \\
(n=881)\end{array}$ & P Value & $\begin{array}{c}\text { Normal } \\
\text { WC } \\
(n=190)\end{array}$ & $\begin{array}{l}\text { Central } \\
\text { obesity } \\
(n=691)\end{array}$ & P Value \\
\hline HbA1c $<7.0 \%$ & $641(45.8 \%)$ & $\begin{array}{c}440 \\
(84.7 \%)\end{array}$ & $\begin{array}{c}201 \\
(22.8 \%)\end{array}$ & $<0.001$ & $\begin{array}{c}144 \\
(75.8 \%)\end{array}$ & $57(8.2 \%)$ & 0.001 \\
\hline $\begin{array}{l}\mathrm{BP} \\
<140 / 90 \mathrm{mmHg}\end{array}$ & $593(42.4 \%)$ & $\begin{array}{c}414 \\
(79.8 \%)\end{array}$ & $\begin{array}{c}179 \\
(20.3 \%)\end{array}$ & $<0.001$ & $97(51 \%)$ & $82(11.8 \%)$ & 0.149 \\
\hline $\begin{array}{l}\text { LDL-C }<100 \\
\mathrm{mg} / \mathrm{dl}\end{array}$ & $607(43.4 \%)$ & $\begin{array}{c}414 \\
(79.8 \%)\end{array}$ & $\begin{array}{c}193 \\
(21.9 \%)\end{array}$ & 0.052 & $\begin{array}{c}107 \\
(56.3 \%)\end{array}$ & $86(12.4 \%)$ & 0.893 \\
\hline $\begin{array}{l}\text { Achieve all } \\
\text { above Targets }\end{array}$ & $267(19 \%)$ & $\begin{array}{c}180 \\
(34.7 \%)\end{array}$ & $87(9.9 \%)$ & $<0.001$ & $51(26.8 \%)$ & $36(5.2 \%)$ & 0.014 \\
\hline
\end{tabular}

Data are shown as n (\%).

\section{Discussion}

Diabetes Mellitus is a major public health problem which has become the leading cause of mortality and morbidity worldwide. Its prevalence is rising in the developing countries especially in India, in response to increasing prosperity and sedentary lifestyles. 
Over weight and obesity are major two consequence of Type 2 Diabetes. Even though it is recommended by all most all diabetes guideline recommend to achieve integrated glycemic, blood pressure and lipid goal, but in realty obese subjects fails to achieve it than normal weight subjects. It was also observed that subjects with central obesity fails in much higher rate to active integrated glycemic, blood pressure and lipid goal. Prevalence of obesity was $63 \%$ as per the BMI criteria $(\geq 25)$ were observed in this study. In a study, prevalence of obesity (BMI $\geq 30 \mathrm{~kg} / \mathrm{m} 2)$ was $54.8 \%$ and combined prevalence of overweight and obesity (BMI $\geq 25 \mathrm{~kg} / \mathrm{m} 2$ ) was $85.2 \%$, conducted among US population ${ }^{[14]}$.

Evidence from some prospective studies in Asia suggests that obesity is directly related to the incidence of diseases such as hypertension, type 2 diabetes, and hypercholesterolemia ${ }^{[14,16,17,18]}$. As per majority of trial reports, waist circumference or waist-to-hip ratio might be more appropriate indices of obesity for Asian people ${ }^{[19,20]}$.

In our study only $19 \%$ subjects were able to achieve their target goal of diabetes, hypertension and dyslipidemia. This trial conducted at Prakash diabetes Hospital OPD confirms the negative effect of obesity and overweight for achieving target therapeutic goal ${ }^{[21,22]}$. In addition to obesity and overweight, there were another risk factor which influence the achievement of target therapeutic goal of type 2 diabetes and hypertension was like style. Sedentary lifestyle and Alcohol consumption were more common in obese than in normal-weight patients. Centrally obese patients were also more likely to be smokers or alcohol drinkers $(\mathrm{P}<0.001)$. Several trial has confirm that, increase insulin sensitivity, oxidation of free fatty acids and glucose disposal may because of decrease in physical activity ${ }^{[23,24]}$.

Drinking alcohol and smoking, in this study has appeared to be independent risk factor and prevent an individual to achieve primary target goal. Frequent exercise and restriction of smoking and drinking habits with exercise regimen and healthy lifestyle may help obese and overweight people to achieve their target goal.

\section{Conclusion}

Hypertension and obesity were associated with poor glycemic control in Indian type 2 diabetes patients at Bihar. To manage the situation a proper clinical awareness and management of obesity and hypertension is essential to achieve target glycemic control among type 2 diabetes subjects.

\section{References}

1. Ranjit Mohan Anjana, Mohan Deepa, Rajendra Pradeepa, Jagadish Mahanta, Kanwar Narain, Hiranya Kumar Das, et al. Prevalence of diabetes and prediabetes in 15 states of India: results from the ICMRINDIAB population-based cross-sectional study. The Lancet Diabetes and Endocrinology, Volume 5, ISSUE 8, P585596, August 01, 2017.

2. McCulloch DK, Robertson RP. Risk factors for type 2 diabetes mellitus Available from: http://www.uptodate.com/contents/riskfactors-for-type-2-diabetes-mellitus.

3. NHS Digital. National Diabetes Audit 20122013: report 1: care processes and treatment targets. Available from: http://www.hscic.gov.uk/catalogue/PUB149 70

4. Lau DCW. New insights in the prevention and early management of type 2 diabetes. Can J Diabetes 2011;35:239-41.

5. World Health Organization Global Action Plan for the Prevention and Control of Noncommunicable Diseases 2013-2020. Geneva, Switzerland: World Health Organization; 2013

6. United Nations Population Division The World Population Prospects: 2015 Revision. New York, NY: United Nations; 2015.

7. Geldsetzer P, Manne-Goehler J, Theilmann $M$, et al. Diabetes and Hypertension in India: A Nationally Representative Study of 
1.3 Million Adults. JAMA Intern Med. 2018;178(3):363-372.

8. Sharma, Shilpi and Jain, Shashi. 2009. Prevalence of obesity among type 2 diabetics. J. Hum. Ecol., 25(1): 31-35.

9. Hossain, Mohammad, Salim, Rahaman, Zahedur, Banik, Sujan, Sarwar, Shahid, Yokota, Kazushige. 2012. Prevalence of the metabolic syndrome in diabetic patients living in a coastal region of Bangladesh.. IJPSR, 3(8): 2633-263.

10. Arner, E, Westermark, PO, Spalding, KL, Britton, T, Ryden, M, Frisen, J, et al, 2010. Adipocyte Turnover: Relevance to Human Adipose Tissue Morphology. Diabetes, 59:105-9.

11. Eriksson J, Lindström J, Tuomilehto J. Potential for the prevention of type 2 diabetes. Oxford Journals, British Medical Bulletin. 2001;60(1):183-99.

12. American Diabetes Association. Diagnosis and classification of diabetes mellitus. Diabetes Care 2018 Jan; 41(Supplement 1): S13-S27.

13. IDF Diabetes Atlas I Sixth edition I 66.

14. Centers for Disease Control and Prevention (CDC). Prevalence of overweight and obesity among adults with diagnosed diabetes-United States, 1988-1994 and 1999-2002. MMWR Morb Mortal Wkly Rep. 2004; 53:1066-1068.

15. Ko GT, Chan JC, Woo J, et al. Simple anthropometric indexes and cardiovascular risk factors in Chinese. Int $\mathbf{J}$ Obes Relat Metab Disord 1997; 21: 995-1001.

16. Yoshiike N, Matsumura Y, Zaman MM, Yamaguchi M. Descriptive epidemiology of body mass index in Japanese adults in a representative sample from the National Nutrition Survey 1990-1994. Int J Obes Relat Metab Disord 1998; 22: 684-87.

17. Oh SW, Shin S-A, Yun YH, Yoo T, Huh BY. Cut-off point of BMI and obesity-related comorbidities and mortality in middle-aged Koreans. Obesity Res 2004; 12: 2031-40.
18. Shin CS, Lee HK, Koh CS, et al. Risk factors for the development of NIDDM in Yonchon County, Korea. Diabetes Care 1997; 20: 1842-46.

19. Ramachandran A, Snehalatha C, Dharmaraj D, Viswanathan M. Prevalence of glucose intolerance in Asian Indians. Urban-rural diff erence and signifi cance of upper body adiposity. Diabetes Care 1992; 15: 1348-55.

20. Ramachandran A, Snehalatha C, Latha E, Vijay V, Viswanathan M. Rising prevalence of NIDDM in an urban population in India. Diabetologia 1997; 40: 232-37

21. Jones DW, Miller ME, Wofford MR, Anderson DC Jr, Cameron ME, Willoughby DL, et al. The effect of weight loss intervention on antihypertensive medication requirements in the hypertension Optimal Treatment (HOT) study. Am J Hypertens. 1999; 12:1175-1180.

22. Fujioka K, Seaton TB, Rowe E, Jelinek CA, Raskin P, Lebovitz HE,et al. Weight loss with sibutramine improves glycaemic control and other metabolic parameters in obese patients with type 2 diabetes mellitus. Diabetes Obes Metab. 2000; 2:175-187.

23. Qin L, Knol MJ, Corpeleijn E, Stolk RP. Does physical activity modify the risk of obesity for type 2 diabetes: a review of epidemiological data. Eur J Epidemiol. 2010; 25:5-12. doi: 10.1007/s10654-0099395-y.

24. Ryan AS, Ge S, Blumenthal JB, Serra MC, Prior SJ, Goldberg AP. Aerobic exercise and weight loss reduce vascular markers of inflammation and improve insulin sensitivity in obese women. J Am Geriatr Soc. 2014; 62:607-614. doi: 10.1111/jgs.12749. 